\title{
DESENVOLVIMENTO DE Dysmicoccus brevipes (Cockerell) (HEMIPTERA:PSEUDOCOCCIDAE) EM DUAS CULTIVARES DE ABACAXI ${ }^{1}$
}

\author{
Development of the pineapple mealybug Dysmicoccus brevipes (Cockerell) \\ (Hemiptera: Pseudococcidae) on two pineapple cultivars
}

\author{
Lenira Viana Costa Santa-Cecília ${ }^{2}$, Vanda Helena Paes Bueno ${ }^{3}$, Ernesto Prado ${ }^{4}$
}

\begin{abstract}
RESUMO
A cochonilha Dysmicoccus brevipes (Cockerell) (Hemiptera: Pseudococcidae) é uma das principais pragas em cultivos de abacaxi e os estudos biológicos desse inseto em diferentes cultivares são uma necessidade. Objetivou-se com este trabalho avaliar o desenvolvimento dessa cochonilha em duas cultivares de abacaxi, Pérola e Cayenne. O experimento foi conduzido em câmara climatizada a $25 \pm 1^{\circ} \mathrm{C}, 70 \pm 10 \%$ UR e fotofase de 12 horas. As plantas de abacaxi foram reproduzidas in vitro, transplantadas para vasos $(250 \mathrm{~mL})$ e aclimatadas em casa-de-vegetação. Ninfas com até um dia de vida foram confinadas em gaiolas de PVC (1 cm de diâmetro), e fixadas em folhas de ambas as cultivares. Não foram detectadas diferenças no desenvolvimento de $D$. brevipes nos dois substratos alimentares utilizados. O desenvolvimento ninfal de fêmeas e machos de $D$. brevipes foi 39,9 e 32,0 dias na cv. Pérola e 38,5 e 32,4 dias na cv. Cayenne, respectivamente. A sobrevivência da fase ninfal foi 32,3 e 40,5\%; a razão sexual, 0,39 e 0,33; e a longevidade de fêmeas, 20,3 e 26,1 dias nas cvs. Pérola e Cayenne, respectivamente.
\end{abstract}

Termos para indexação: Insecta, cochonilha-do-abacaxi, Ananas comosus (L.) Merril, biologia.

\section{ABSTRACT}

The pineapple mealybug Dysmicoccus brevipes (Cockerell) (Hemiptera: Pseudococcidae) is the main pest on pineapple crops and biological studies of this insect are necessary on different cultivars. The objective of this work was to evaluate the development time of this mealybug on the pineapple cultivars Pérola and Cayenne. The experiment was performed in climated chambers at $25 \pm 1^{\circ} \mathrm{C}, 70 \pm 10 \% \mathrm{RH}$ and $12 \mathrm{~h}$ photophase. Pinneapple plants were reproduced in vitro, transplanted to pots (250 $\mathrm{mL})$ and kept in greenhouse. One-day-old nymphs were kept inside a clipcage $(1 \mathrm{~cm}$ diameter) fixed on the plants. No differences in development of $D$. brevipes among the cultivars were found. Development times of females and males, respectively, were 39.9 and 32 days on cv. Pérola and 38.5 and 32.4 days on cv. Cayenne. Nymphs survivals were 32.3 and 40.5\%, sexual rates were 0.39 and 0.33 , and females longevities were 20.3 and 26.1 days on cv. Pérola and Cayenne, respectively.

Index terms: Insect, pineapple mealybug, Ananas comosus (L.) Merril, biology.

(Recebido para publicação em 7 de novembro de 2003 e aprovado em 16 de junho de 2004)

\section{INTRODUÇÃO}

A cochonilha Dysmicoccus brevipes (Cockerell) (Hemiptera: Pseudococcidae) vem ocorrendo nos abacaxizais do Brasil desde 1931, sendo seus prejuízos a causa do declínio da cultura em muitas áreas do Estado de São Paulo e, posteriormente, de Minas Gerais (HAMBLETON, 1935; SANTA-CECÍLIA e CHALFOUN, 1998).

Adultos e ninfas vivem em colônias e localizam-se nas raízes e axilas das folhas. Contudo, quando ocorre um grande aumento de sua população, podem ser também observados nas inflorescências, nos pedúnculos, nas infrutescências do abacaxi e nas mudas que crescem ao redor da infrutescência (SANTA-CECÍLIA e CHALFOUN, 1998). A cochonilha ocasiona o enfraquecimento das plantas devido à sucção da seiva, além de estar associada a uma doença de origem virótica conhecida como murcha-doabacaxizeiro (GUNASHINGHE e GERMAN, 1987; 1989), a qual impede a frutificação normal, podendo ocasionar também a morte das plantas antes do período reprodutivo; os prejuízos podem ultrapassar os $50 \%$ (SANCHES, 1997). Assim, esse complexo, c ochonilha e murcha-do-abacaxizeiro, tem-se constituído em um dos maiores entraves para o aumento da produtividade da cultura no Brasil.

1. Parte da tese apresentada à Universidade Federal de Lavras/UFLA, Caixa Postal 3037 - 37200-000 - Lavras, MG, para obtenção do título de "Doctor Scientiae".

2. Pesquisadora, D.Sc., Empresa de Pesquisa Agropecuária de Minas Gerais/EPAMIG/CTSM/EcoCentro - Caixa Postal 176, 37200-000 - Lavras, MG. scecilia@epamig.ufla.br

3. Professora, D.Sc., Departamento de Entomologia, UFLA

4. Pesquisador, D.Sc., Instituto de Investigaciones Agropecuárias/INIA - Chile. 
Poucas pesquisas foram realizadas sobre a biologia de $D$. brevipes, sendo escassas as informações sobre o seu desenvolvimento associado a diferentes cultivares de abacaxi. Giacomelli e Py (1981) relataram diferenças de susceptibilidade à murcha entre cultivares, sendo a cv. Cayenne (grupo Cayenne) mais susceptível quando comparada à cv. Pérola (grupo Pernambuco). A susceptibilidade à murcha pode estar associada ao patógeno, à própria planta ou ao efeito dessa sobre a cochonilha.

Considerando a necessidade de estudos básicos que conduzam ao conhecimento da interação insetoplanta, com este trabalho objetivou-se avaliar o desenvolvimento de $D$. brevipes em duas cultivares de abacaxi, Pérola e Cayenne.

\section{MATERIAL E MÉTODOS}

\section{Criação de manutenção de $D$. brevipes}

Adultos da cochonilha foram obtidos em plantios de abacaxi no município de Piumhí/MG (Região do Alto São Francisco) e infestados em plantas da cv. Cayenne, com cerca de seis meses de idade, cultivadas em vasos com capacidade para 20 litros. Essa criação foi mantida em casa-de-vegetação do Departamento de Entomologia da Universidade Federal de Lavras/UFLA, Lavras - MG, objetivando a produção de insetos necessários à implantação do experimento.

\section{Cultivares de abacaxi}

As cultivares de abacaxi utilizadas foram Pérola, também conhecida como Pernambuco ou Branco de Pernambuco, e Cayenne, também conhecida como Smooth Cayenne ou Cayenne Lisse, as quais são incluídas nos grupos 4 e 1, respectivamente. Essa classificação tem como base um conjunto de caracteres comuns, entre os quais se destacam o porte da planta, forma da infrutescência, característica da polpa e morfologia da folha, em particular a presença ou ausência de espinhos (CABRAL, 1985). Outras denominações dessas cultivares utilizadas em outros países foram relatadas por Py et al. (1984).

As plantas foram obtidas in vitro pelo fato de serem mais adequadas ao manuseio por ocasião das avaliações ao microscópio estereoscópico para visualização das ninfas, e também por proporcionarem um melhor ajuste das unidades de criação das cochonilhas nas folhas. Essas plantas foram produzidas no Laboratório de Cultura de Tecidos do Departamento de Agricultura da Universidade Federal de Lavras/UFLA, sendo posteriormente transplantadas em potes plásticos (250 mL), utilizando- se o substrato Plantmax ${ }^{\circledR}$ e aclimatadas em casa-devegetação até a formação de 5-6 pares de folhas, quando foram usadas nos estudos.

\section{Desenvolvimento de $D$. brevipes em duas cul-} tivares de abacaxi

O estudo foi conduzido no Laboratório de Controle Biológico de Pragas do Centro de Manejo Ecológico de Pragas e Doenças de Plantas - EcoCentro/ CTSM-EPAMIG, Lavras - MG, em câmara climatizada ajustada a $25 \pm 1^{\circ} \mathrm{C}, 70 \pm 10 \%$ UR e 12 horas de fotofase.

A metodologia utilizada foi baseada em estudos realizados por Menezes (1973). Fêmeas adultas oriundas da criação de manutenção foram coletadas com um pincel de cerdas finas e mantidas em câmara climatizada. As ninfas da primeira geração, com até um dia de vida, foram individualizadas e encerradas em gaiolas de PVC transparente $(10 \mathrm{~mm}$ de diâmetro por $11 \mathrm{~mm}$ de altura), vedadas em sua parte superior com tela de nylon (0,2 mm de malha), suficiente para evitar a fuga dos insetos. Na parte da gaiola em contato com a folha, foi colada uma fina camada de espuma, com espessura de $1 \mathrm{~mm}$, para melhor ajuste à folha do abacaxizeiro e promover maior vedação. Esses recipientes foram identificados e fixados com clipes de metal nas folhas das duas cultivares. Cada planta foi identificada e colocada em câmara climatizada.

Diariamente, as plantas foram observadas em microscópio estereoscópico, visando ao acompanhamento do desenvolvimento da cochonilha, o que era realizado sem o manuseio das ninfas e/ou gaiolas, pois, sendo transparentes, permitiam a perfeita visualização dos insetos.

Foram avaliados o número, a duração e sobrevivência de cada ínstar, a duração e sobrevivência da fase ninfal, a razão sexual e a longevidade de fêmeas. Não foi avaliada a longevidade dos machos, visto que esses não emergem logo após a última ecdise, permanecendo mais alguns dias no interior do casulo até atingirem a maturidade sexual (ITO, 1938; MENEZES, 1973). Tentou-se o manuseio do casulo, entretanto, não se obteve sucesso, pois tal procedimento ocasionava a morte dos adultos.

O delineamento experimental foi o inteiramente casualizado, e para a duração do primeiro e segundo ínstares e período ninfal de $D$. brevipes, os tratamentos foram dispostos em esquema fatorial 2x2 (cultivares e sexo), utilizando-se 29 plantas para cada cultivar e 8 cochonilhas por planta. Para os demais parâmetros avaliados na fase jovem, não foi considerado o sexo dos insetos. Como a diferenciação sexual é difícil de ser constatada no início do desenvolvimento ninfal, as repetições foram constituídas por in- 
divíduos com sexo não conhecido. Também, devido à mortalidade de ninfas nos primeiros ínstares, obteve-se um número diferenciado de insetos dentro de cada repetição, resultando em um delineamento experimental desbalanceado.

\section{Análise dos dados}

Para cultivar e sexo, foi realizada a análise de variância, e as médias dentro de cada instar e do período ninfal foram comparadas pelo teste de Tukey.

Para o cálculo da sobrevivência do primeiro e segundo ínstares e período ninfal, não foi feita a separação dos insetos por sexo, pois alguns morreram nos primeiros dias de cada ínstar, não sendo possível a diferenciação sexual, porém, foram considerados na análise estatística (teste "t" de Student).

Os dados de longevidade de fêmeas e razão sexual foram analisados pelo teste "t"; para os de longevidade utilizou-se a transformação $\sqrt{x+1}$.

\section{RESULTADOS E DISCUSSÃO}

\section{Número de ínstares}

O desenvolvimento ninfal dos machos de $D$. brevipes constou de dois ínstares livres; no final do segundo, eles constroem um casulo de filamentos cerosos em cujo interior passam para as fases de pré-pupa, pupa e adulta, seguindo-se a emergência após a maturidade sexual. Já as fêmeas apresentaram um desenvolvimento paurometabólico, com três ínstares seguidos da fase adulta. Essas observações assemelham-se àquelas verificadas por Ito (1938), Lim (1973), Menezes (1973) e Colen et al. (2000) para essa mesma espécie de cochonilha.

\section{Duração dos ínstares}

Não foram detectadas diferenças significativas para o desenvolvimento das fases imaturas de fêmeas e machos de $D$. brevipes em função da cultivar de abacaxi avaliada (Figura 1).

O primeiro ínstar das fêmeas apresentou durações médias de 11,3 \pm 0,8 dias na cv. Pérola e 12,7 \pm 0,6 dias na cv. Cayenne, valores superiores ao encontrado por Menezes (1973) (7,4 dias) e próximos àquele obtido por Lim (1973) (10 dias), não sendo relatados pelos autores os grupos a que pertencem as cultivares de abacaxi utilizadas. Para os machos, esse ínstar teve uma duração média de 12,2 \pm 0,6 dias na cv. Pérola e 11,3 \pm 0,6 dias na cv. Cayenne, resultados superiores aos obtidos por Menezes (1973) e Lim (1973), que constataram 7,2 e 9,9 dias, respectivamente.

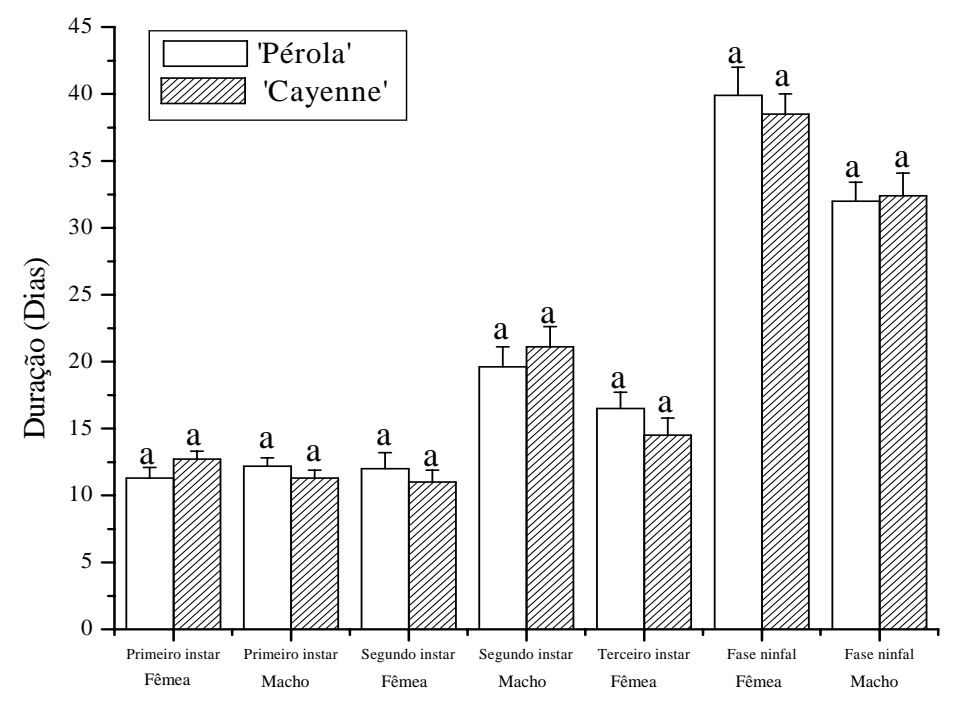

FIGURA 1 - Duração dos ínstares e da fase ninfal de fêmeas e machos de Dysmicoccus brevipes em duas cultivares de abacaxi, Pérola e Cayenne. 
Verificou-se uma grande semelhança entre machos e fêmeas desse ínstar e, independentemente da cultivar, os valores encontrados para ambos os sexos foram bem próximos.

No segundo ínstar, as fêmeas apresentaram uma duração média de 12,0 \pm 1,2 dias na cv. Pérola e de 11,0 $\pm 0,9$ dias na cv. Cayenne, valores próximos aos encontrados por Colen et al. (2000) (12,4 dias para essa cultivar). Menezes (1973) obteve para esse ínstar uma duração de 10,6 dias.

A duração média do segundo ínstar do macho foi de 19,6 \pm 1,5 dias na cv. Pérola e de 21,1 \pm 1,5 dias na cv. Cayenne, valores semelhantes aos obtidos por Colen et al. (2000), que constataram uma duração de 21,5 dias na cv. Cayenne, próximos daqueles encontrados por Menezes (1973) (19,4 dias) e superiores aos obtidos por Lim (1973) (12,0 dias).

Nesse ínstar, os machos apresentaram um período de desenvolvimento maior do que as fêmeas, independentemente do substrato alimentar em que se criaram. Entretanto, cabe ressaltar que na duração do segundo ínstar do macho, foi incluído todo o período de desenvolvimento ocorrido no interior do casulo.

Para o terceiro ínstar das fêmeas, obteve-se, em média, na cv. Pérola, uma duração de 16,5 \pm 1,2 dias e $14,5 \pm 1,3$ dias na cv. Cayenne. Esses resultados aproximaram-se daqueles obtidos por Colen et al. (2000) (12,7 dias), para D. brevipes criada na cv. Cayenne, porém, diferiram daqueles observados por Menezes (1973) (39,9 dias).

\section{Período ninfal}

Não foi verificada diferença significativa no período ninfal de fêmeas e machos em função da cultivar (Figura 1). O valor médio (39,9 \pm 2,1 dias) encontrado para fêmeas criadas na cv. Pérola não diferiu daquele encontrado na cv. Cayenne (38,5 \pm 1,5 dias). Para os machos, constatou-se na cv. Pérola uma duração média de 32,0 \pm 1,4 dias e 32,4 \pm 1,7 dias na cv. Cayenne. Colen et al. (2000) verificaram valores próximos a esses, sendo 39,4 dias para fêmeas e 33,1 dias para machos, quando esses alimentaram-se de plantas da cv. Cayenne. Entretanto, foram superiores àqueles obtidos por Lim (1973) (23,5 dias para fêmeas e 24,0 dias para machos) e por Menezes (1973) (25,1 dias para machos de $D$. brevipes). Já para as fêmeas, esse último autor verificou uma duração de 58 dias.
Houve influência do sexo na duração da fase ninfal de $D$. brevipes, constatando-se, em média, 39,2 dias para as fêmeas e 32,2 dias para os machos. Comparando-se a duração do período ninfal de fêmeas e machos em ambas as cultivares, observou-se que o macho emerge antes da fêmea. Apesar de o curto período de vida dos machos adultos, a sobreposição de gerações assegura o encontro dos sexos na natureza.

\section{Sobrevivência}

Não houve diferença na sobrevivência dos ínstares e da fase ninfal da cochonilha em função da cultivar de abacaxi (FIGURA 2). A sobrevivência no primeiro ínstar foi 64,7 e 69,8\% para as cvs. Pérola e Cayenne, e no segundo ínstar, 61,0 e 65,8\% para ambas as cultivares, respectivamente, sendo constatado um ligeiro aumento (75,0 a 79,5\%) no terceiro ínstar da fêmea.

Em ambas as cultivares, a sobrevivência da fase ninfal de $D$. brevipes foi 32,3 e 40,5\% para as cvs. Pérola e Cayenne, respectivamente (Figura 2).

\section{Razão sexual}

O substrato alimentar não afetou a razão sexual de $D$. brevipes, sendo constatada a emergência de 29 fêmeas e 46 machos na cv. Pérola e 32 fêmeas e 66 machos na Cayenne. Diferentemente, Ito (1938) obteve variação na razão sexual dessa espécie de cochonilha quando houve mudança de hospedeiro e ambiente.

Os valores encontrados para a razão sexual (0,39 e 0,33 para as cvs. Pérola e Cayenne, respectivamente) estão próximos aos obtidos por Colen et al. (2000), os quais constataram uma razão sexual de 0,39. Porém, diferiram daqueles encontrados por Lim (1973) e Menezes (1973), que obtiveram 0,50 e 0,65, respectivamente.

\section{Longevidade de fêmeas}

Não foi verificada diferença significativa na longevidade de fêmeas em função do substrato alimentar (FIGURA 3); na cv. Pérola, o valor médio (20,3 \pm 2,9 dias) não diferiu daquele encontrado na cv. Cayenne (26,1 \pm 2,5 dias), resultado semelhante ao encontrado por Colen et al. (2000) para essa espécie mantida nessa cultivar (26,6 dias). Lim (1973) obteve 28,1 dias para longevidade de fêmeas à temperatura de $29 \pm 3^{\circ} \mathrm{C}$. 


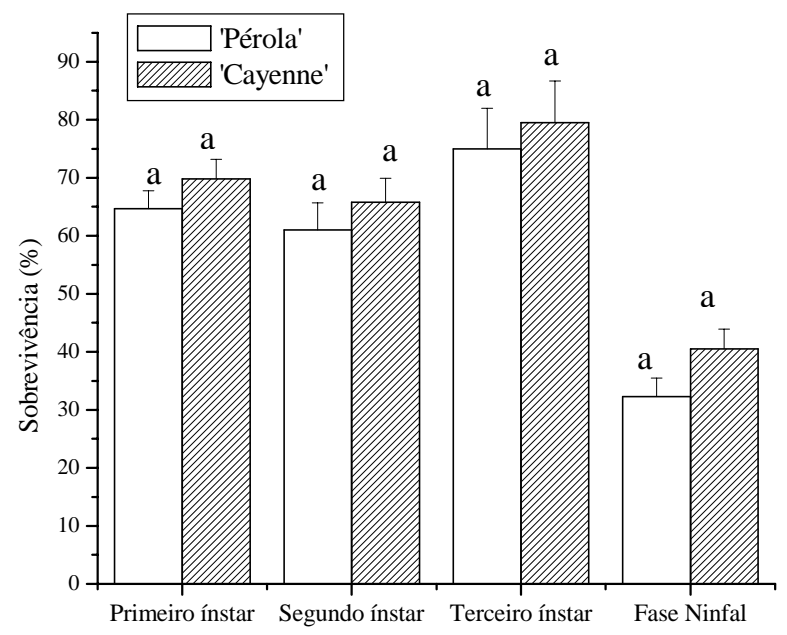

FIGURA 2 - Porcentagem de sobrevivência dos ínstares e da fase ninfal de Dysmicoccus brevipes mantidas em duas cultivares de abacaxi, Pérola e Cayenne.

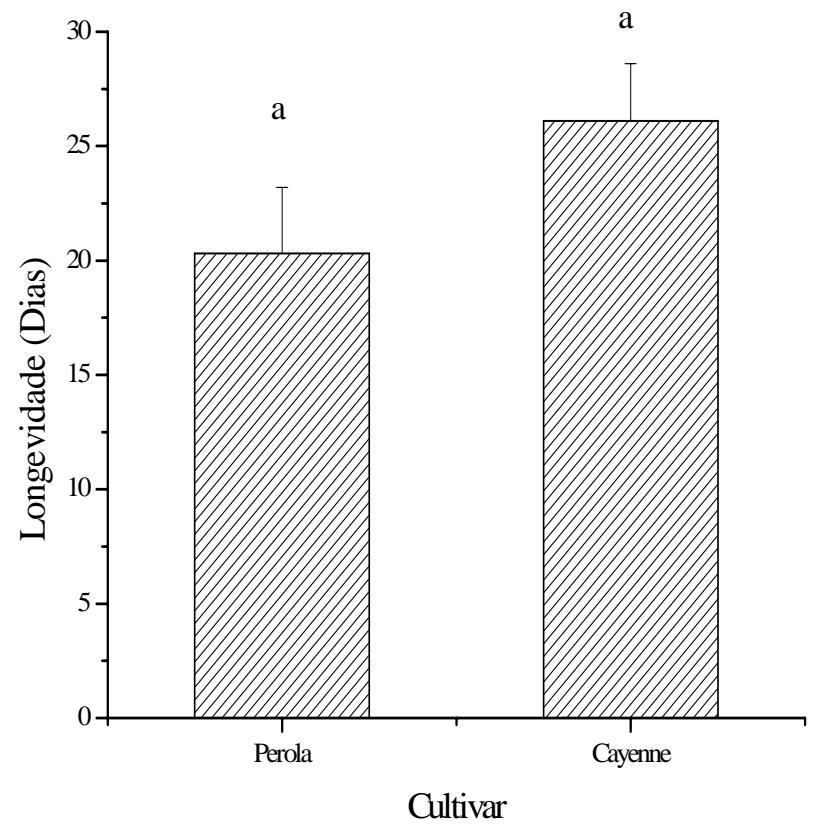

FIGURA 3 - Longevidade de fêmeas de Dysmicoccus brevipes em duas cultivares de abacaxi, Pérola e Cayenne.

\section{CONCLUSÃO}

O desenvolvimento de $D$. brevipes foi similar nas cvs. Pérola e Cayenne, evidenciando um mesmo efeito dessas plantas sobre a biologia dessa cochonilha.

\section{AGRADECIMENTOS}

À Fundação de Amparo à Pesquisa do Estado de Minas Gerais (FAPEMIG), pela concessão de recursos financeiros e bolsa de estudo, que possibilitaram a realização desta pesquisa. E à Lúcia Aparecida Mendonça, pelo auxílio na confecção dos gráficos. 


\section{REFERÊNCIAS BIBLIOGRÁFICAS}

CABRAL, J. R. S. Caracterização e avaliação de cultivares de abacaxi. Informe Agropecuário, Belo Horizonte, v. 11, n. 130, p. 14-16, out. 1985.

COLEN, K. G. F.; SANTA-CECÍLIA, L. V. C.; MORAES, J. C.; REIS, P. R. Efeitos de diferentes temperaturas sobre a biologia da cochonilha pulverulenta Dysmicoccus brevipes (Cockerell, 1893) (Hemiptera: Pseudococcidae). Revista Brasileira de Fruticultura, Jaboticabal, v. 22, n. 2, p. 248-252, ago. 2000.

GIACOMELLI, E. J.; PY, C. O abacaxi no Brasil. Campinas: Fundação Cargill, 1981. 101 p.

GUNASHINGHE, U. B.; GERMAN, T. L. Further characterization of a virus associated with mealybugwilt of pineapple. Phytopathology, Saint Paul, v. 77, n. 12, p. 1776, Dec. 1987.

GUNASHINGHE, U. B.; GERMAN, T. L. Purification and partial characterization of a virus from pineapple. Phytopathology, Saint Paul, v. 79, n. 12, p. 1337-1341, Dec. 1989.

HAMBLETON, E. J. Notas sobre Pseudococcinae de importância econômica no Brasil com a descrição de quatro espécies novas. Arquivos do Instituto Biológico, São Paulo, v. 6, n. 13, p. 105-120, 1935.
ITO, K. Studies on the life history of the pineapple mealybug, Pseudococcus brevipes, (Ckll). Journal of Economic Entomology, Honolulu, v. 31, n. 2, p. 291-298, Apr. 1938.

LIM, W. H. Studies on the bissexual race of Dysmicoccus brevipes (Ckll), its bionomics and economic importance. Malaysian Agricultural Journal, Kuala Lumper, v. 49, n. 2, p. 254-267, 1973.

MENEZES, E. B. Bioecologia e controle da cochonilha farinhosa do abacaxi Dysmicoccus brevipes (Cockerell, 1893) Ferris, 1950 (Homoptera: Pseudococcidae). 1973. 77 p. Dissertação (Mestrado em Entomologia) - Escola Superior de Agricultura Luiz de Queiroz, Piracicaba, 1973.

PY, C.; LACOEUILHE, J. J.; TEISSON, C. L'ananas as culture: ses produits. Paris: G. P. Maisonneuve et Larouse, 1984. 562 p.

SANCHES, N. F. Índices de infestação da cochonilha Dysmicoccus brevipes (Hemiptera: Pseudococcidae) em abacaxizeiro sob regime de irrigação. In: CONGRESSO BRASILEIRO DE ENTOMOLOGIA, 16., 1997, Salvador. Resumos... Salvador: EMBRAPA/CNPMF, 1997. p. 220.

SANTA-CECÍLIA, L. V. C.; CHALFOUN, S. M. Pragas e doenças que afetam o abacaxizeiro. Informe Agropecuário, Belo Horizonte, v. 19, n. 195, p. 40-47, 1998. 